\title{
Para além de um prefácio: ditadura e democracia no diálogo entre Antonio Candido e Sérgio Buarque de Holanda
}

\author{
Beyond the preface: dictatorship and democracy in Antonio \\ Candido and Sérgio Buarque de Holanda's dialogue
}

\author{
Thiago Lima Nicodemo*1
}

\section{Resumo}

Partindo de uma análise das temporalidades subjacentes ao Prefácio de Raízes do Brasil, de 1969, este artigo estuda a colaboração entre Antonio Candido e Sérgio Buarque de Holanda. Seguindo o percurso de um esboço de biografia cruzada, o texto atenta para a cumplicidade e para a apropriação colaborativa de certas ideias chave presentes em outras obras desses autores, como Monções (1945), Caminhos e fronteiras (1957), Capitulos de literatura colonial (1991), Parceiros do Rio Bonito (1964) e Formação da literatura brasileira (1959). De modo geral, as análises dos dois confluem numa representação do trabalho intelectual enquanto forma de engajamento e militância política em face da experiência da ditadura (Estado Novo, 1937-1945, e Regime Militar, 1964-1985) e nas expectativas em relação à democratização.

Palavras-chave: Sérgio Buarque de Holanda; Antonio Candido; biografia intelectual; história cruzada; memória.

\section{Abstract}

This text analyses Antonio Candido's 1969 preface to Raizes do Brasil (Roots of Brazil, 1936) assessing its underlying layers of temporality; especially regarding the previous dialogues between Antonio Candido, author of the referred preface, and Sérgio Buarque de Holanda, author of the book. By doing so, it seeks to present a sketch of a collective or "entangled" biography: taking in consideration the mutual appropriation and a certain complicity present as key concepts on theirs texts, such as Monções (1945), Caminhos e fronteiras (1957), Capitulos de literatura colonial (1991), Formação da literatura brasileira (1959) and Parceiros do Rio Bonito (1964). In summary, both Candido and Holanda's analysis converge to a representation of the intellectual craft as a form of political engagement facing two dictatorships (Estado Novo, 1937-1945, and Military Dictatorship, 1964-1985), and the aspirations for democracy during and after each authoritarian regime.

Keywords: Sérgio Buarque de Holanda; Antonio Candido; collective biography; entangled History; memory.

\footnotetext{
* Departamento de História e Programa de Pós-Graduação, Universidade do Estado do Rio de Janeiro (Uerj). Rio de Janeiro, RJ, Brasil. tnicodemo@gmail.com
} 
Em obra recente, Signo e desterro (2015), Pedro Meira Monteiro aponta para o papel de Antonio Candido como responsável pela "construção paulatina de um campo de interpretação em torno a Sérgio Buarque" (Monteiro, 2015, p.36). Nos textos de Candido sobre Sérgio Buarque, a começar pelo famoso prefácio à $5^{a}$ edição de Raízes do Brasil, de 1969, nota-se o esforço para a construção de "coerência política e conceitual" em torno tanto de Raízes do Brasil quanto da trajetória de seu autor. Trocando em miúdos, Monteiro se indaga se Sérgio Buarque, enquanto um "radical” pensador de esquerda, não é um "personagem" que emerge das leituras de Antonio Candido. ${ }^{2}$

O peso do prefácio a Raízes do Brasil realmente não pode ser subestimado. Por um lado, sua dimensão enquanto produtor de um "cânone" de leitura sobre os intérpretes do Brasil, o tema vem há muito sendo observado pela crítica (Franzini, 2010, p.17-19; Bresciani, 2005, p.23; Sanches, 2012, p.201202). Não se pode deixar de levar em consideração que o prefácio realmente impulsionou a leitura e recepção do livro. Para visualizar isso basta ter em conta que, nos 30 primeiros anos após a sua publicação, teve apenas quatro edições e, de lá para cá, foram 23 (a atual é a $27^{\mathrm{a}}$ ), sem considerar duas edições comemorativas: a de 70 anos, publicada em 2006, e a nova edição crítica, comemorativa de 80 anos, publicada em 2016, ambas pela Companhia das Letras. O próprio Sérgio Buarque de Holanda chegou a ironizar a ampliação do interesse sobre sua obra, dizendo, em uma de suas últimas entrevistas, que o prefácio de Candido "deu sorte" (Holanda, 2004, p.10).

No prefácio, Candido afirma que Raízes do Brasil era um "clássico de nascença" por sua "atualidade", já que em 1936 Sérgio Buarque pautava sua reflexão "a respeito das condições de uma vida democrática no Brasil" (Candido, 1995, p.19). Como veremos mais à frente, ao fazer isso, reforça um sentido da obra que só se torna claro com as revisões publicadas em 1948 e 1956. Na década de 1980, Candido segue investindo na ideia, em textos como "Sérgio em Berlin e depois" (1982) e "Radicalismos" (conferência de 1988, publicada em 1990). A ideia é que "radical" consiste no intelectual que, opondo-se aos interesses de sua própria classe, forma um "contrapeso ao movimento conservador que sempre predominou" (Candido, 1990, p.4). Combatendo o autoritarismo que predominava na nossa herança, Sérgio Buarque procurava vislumbrar formas para viabilizar "o advento das camadas populares à liderança" (Candido, 1982, p.9).

Neste texto procuro demonstrar que Candido não "inventou” Raízes do Brasil, mas é uma espécie de sócio ou "padrinho" (Eugênio, 2011, p.398) de 
certas linhas gerais de interpretação do Brasil associadas a Sérgio Buarque de Holanda. Seguindo a sugestão de François Dosse de uma biografia intelectual cruzada de Gilles Deleuze e Félix Guattari, trata-se de, para além do horizonte de análise da "escrita de si", compreender justamente o entre-lugar, cruzamento entre duas subjetividades que formam algo novo (Dosse, 2010, p.1).

A questão abordada se relaciona intrinsecamente com o problema da memória, entendido em sua grande complexidade, e por um prisma sobretudo hermenêutico. Afinal, o texto pode contribuir para compreender melhor como certas interpretações sobre o Brasil se tornaram predominantes, na medida em que foram construídas na agregação de estratos de tempo e de significados (Franzini; Gontijo, 2009). Os condicionantes que formaram nosso próprio olhar, bem como nossas práticas acadêmicas, podem ser encarados como significantes mnemônicos contingentes, que clamam por interpretações mnemônicas regressivas, partindo do presente e indo ao passado, considerando as várias camadas de historicidade que ajudaram a dar forma a um objeto ou tema, tal qual nos foi legado (Feindt, 2014, p.36).

O texto se propõe como um exame desses estratos sobrepostos de temporalidade, e, para isso, parte da análise das camadas de memória subjacentes ao prefácio a Raízes do Brasil. Na cumplicidade de Candido reverberam uma trajetória de intensa colaboração, desde a militância contra o Estado Novo, a crítica literária e o interesse de ambos na cultura interiorizada do caipira e do bandeirante, dentre outros. A noção de "radicalidade", do modo como foi sendo construída ao longo do tempo, pode ser entendida como um dispositivo que aproxima análise acadêmica e horizonte político. No entrecruzamento entre a experiência da ditadura e a esperança de democratização do Brasil (contando tanto o Estado Novo, quanto a ditadura civil-militar) forma-se um dispositivo que atualiza os sentidos políticos das práticas intelectuais.

\section{COMbATES NA MEMÓRIA PELA DEMOCRACIA}

Uma trama intrincada de memórias subjaz à construção da persona "radical" de Sérgio Buarque de Holanda. Sua tessitura é composta pelo entrecruzamento de fios que vêm do passado e do futuro, sobrepondo planos do antes e do depois em um arranjo de aparência sólida e organizada. O olhar lançado a partir do agora, do presente, pode desarrumar a aparente organização, atentando a outros arranjos, e certos fios antes de aparência sólida se soltam, 
enquanto outros podem se unir formando novos conjuntos de significado. Sendo assim, pensando a partir de certas demandas mais imediatas do presente, emerge como problema o papel do autor na elaboração do repertório simbólico da transição democrática do Brasil.

Não se pode perder de vista que a popularização de Raízes do Brasil, a partir de finais da década de 1960, e a suposta invenção de uma persona "radical" são diretamente relacionadas. Essa relação não passa despercebida por Pedro M. Monteiro, mas foi tratada em tese de doutorado por Rafael Pereira da Silva, de 2015. Segundo esse autor, ao argumentar que a obra continha um radicalismo democrático e compromisso com o povo, Antonio Candido influenciava uma geração, pois inscrevia a obra na contracorrente da ditadura civil-militar que então endurecia (Silva, 2015, p.61). O trabalho de Silva contribui decisivamente para a compreensão dessa questão, pois vai para além do prefácio, mostrando como a imagem de Sérgio Buarque "radical" é construída. Em um primeiro momento com ele ainda em vida, posicionando-se contra a ditadura na imprensa, na sua colaboração com o Centro Brasil Democrático e na fundação do Partido dos Trabalhadores; e, em um segundo momento, após sua morte, analisando desde a liturgia do velório, as primeiras homenagens, até a compra da biblioteca e consolidação do arquivo, incorporados pela Unicamp.

O prefácio, portanto, não se esgota em si mesmo. Ele sofre um processo de apropriação nos anos posteriores ao seu lançamento, compondo parte da constelação da redemocratização. Com o "refluxo das utopias revolucionárias" (Ridenti, 2000, p.355), quando paulatinamente a pauta da oposição ao regime militar passa a se concentrar nos temas da democracia e da cidadania, a imagem de Sérgio Buarque e de sua obra ganham força. Dimensão que pode ser medida na própria construção da identidade fundacional do Partido dos Trabalhadores, enquanto imbuído da missão de congregar a esquerda no sentido de um ajuste inclusivo da população (Ridenti, 2000, p.357), fazendo que o "Estado se torne expressão da sociedade", como diz o próprio texto.

Olhando para essa dimensão tão ampla, que é a produção de uma memória mais ou menos convergente sobre o regime militar (Napolitano, 2014, p.335) como elemento fundamental do repertório simbólico da redemocratização do Brasil, parecerá certamente exagerado atribuir a Antonio Candido a “invenção" de Raízes do Brasil (Eugênio, 2011, p.395). ${ }^{3}$ Esse movimento pode ser enquadrado em uma trajetória que merece aprofundamento, em que signos do pensamento sobre o Brasil confluem naquele período em algo que pode ser 
caracterizado como atmosfera pautada por um senso de revisão histórica e de reconstrução nacional. Candido e Sérgio são então personagens importantes, assim como são tantos outros que colaboraram na fixação de certos significados do que entendemos como democracia (e ditadura) e cidadania num projeto de Brasil moderno, reorganizado a partir do outono da ditadura civil-militar.

Candido não inventou Raízes, pois o próprio Sérgio Buarque, ao longo de sua vida, teve papel importante nesse processo, seja estreitando o sentido de coerência de sua obra, seja investindo na construção de sua autoimagem. ${ }^{4}$ Essa é uma conclusão interessante, possibilitada por um adensamento na crítica recente à obra do historiador; tornou-se senso comum entre os especialistas afirmar ser impossível compreender Raízes do Brasil sem atentar para as modificações entre as edições, especialmente a segunda, de 1948, e a terceira, de 1956 (que estabeleceu o texto da forma como conhecemos). Em um cuidadoso estudo a esse respeito, intitulado Ritmo espontâneo, João Kennedy Eugênio demostra como o viés claramente democrático e progressista de Raízes do Brasil só se configura com as modificações da segunda edição. Na realidade, Raízes do Brasil, original de 1936, tem caráter muito mais contraditório, sendo, nesse sentido, um produto típico dos anos 1930. Isso inclui um debate com tendências organicistas e vitalistas de fundo conservador, amparado em autores como Ludwig Klages, Oswald Spengler e Carl Schmitt, de modo que, seguindo uma sugestão de Leopoldo Waizbort (2011), pode-se questionar, decisivamente, a adesão de Sérgio Buarque a qualquer ideal democrático na primeira edição de Raízes do Brasil.

Esses estudos demonstram que o principal responsável pela "invenção" de Raízes do Brasil foi o próprio Sérgio Buarque de Holanda (Eugênio, 2011, p.398). Um argumento que vai além e ainda parece merecer maior atenção é o de que as modificações em seu primeiro livro produzem um poderoso sentido de unidade para todo o trabalho. Quando revisou Raízes, o autor já havia escrito Monções (1945), e estava em processo de redação dos artigos que dariam origem a Caminhos e fronteiras (1957), e também aos originais que viriam a ser Capítulos de literatura colonial, texto também responsável pelo embrião de Visão do Paraíso (1958) (Nicodemo, 2014b, p.331-335). Como veremos mais adiante, essa revisão e ajuste não ocorreu apenas em um plano individual, mas dependeu em boa medida de uma relação colaborativa com Candido, nesses mesmos anos. 


\section{A MEMória DE oUtras ditaduras: os ECos do Estado Novo}

A certa altura da vida, vai ficando possível dar balanço no passado sem cair em autocomplacência, pois o nosso testemunho se torna registro da experiência de muitos, de todos que, pertencendo ao que se denomina uma geração, julgam-se a princípio diferentes uns dos outros e vão, aos poucos, ficando tão iguais, que acabam desaparecendo como indivíduos para se dissolverem nas características gerais da sua época. (Candido, 1995, p.9)

Talvez tenha ainda passado despercebido pela crítica que no discurso "geracional" do prefácio de Antonio Candido a Raízes do Brasil ecoa uma outra avaliação da mesma natureza, publicada no começo de sua carreira, em 1943, o "Plataforma da nova geração". ${ }^{5}$ O texto do final dos anos 1960 inicia se autorizando a falar em termos geracionais, depois de transcorridas décadas, enquanto o texto de 1940 começa justamente com um "sou contra ... esse negócio de geração". Pois, "na idade em que estou [25 anos], soa terrivelmente falso" (Candido, 2002, p.237). Candido fala em duas gerações importantes antes da sua, a da "gente de 22 " e a "de 30 ", sendo que, a partir desta última, "começa a literatura brasileira", no sentido de que "surgem os escritores que pouco devem ao modelo estrangeiro" (p.239); além disso, surgem "os estudiosos que começam a sistematizar o estudo do Brasil e proceder à analise generalizada dos seus problemas". Enquanto "22" "foi mais um estouro de enfants-terribles", "30" era marcada por um "historicismo grande-burguês de Gilberto Freyre, e também o realismo histórico de Caio Prado Júnior” (p.240). Esses dois intelectuais, junto a outros como Sérgio Buarque de Holanda, Afonso Arinos de Melo Franco, Almir de Andrade e Arthur Ramos, representavam uma "orientação intelectual” delineada "na atmosfera de suas lutas políticas” (p.240).

O eco de "Plataforma da nova geração" no prefácio de 1967 não se resume apenas à referência aos ensaios da década de 1930, mas sobretudo à relação entre o pensamento e a política. No ensaio de 1943, Candido demonstra preocupação em relação ao sentido político de tendências de pensamento correntes nos anos 1930, tais como "as filosofias idealistas, a sociologia cultural e a literatura personalista" (p.246) que, de modo geral, identificava com valores políticos do conservadorismo e tradicionalismo. No prefácio de 1967 completa o raciocínio, atribuindo a Raízes do Brasil o papel de fornecer aos jovens "indicações importantes para compreenderem o sentido de certas posições políticas daquele momento" (Candido, 1995, p.10). Considerando Casa-grande e 
Formação, tínhamos uma visão de Brasil que contemplava os pontos de vista de sua geração, pois "traziam a denúncia do preconceito de raça, a valorização do elemento de cor, a crítica dos fundamentos "patriarcais" e agrários, o discernimento das condições econômicas, a desmistificação da retórica liberal" (Candido, 1995, p.11). Trata-se, portanto, de alusões críticas a correntes ideológicas que abasteceriam os totalitarismos, e, em particular, o Estado Novo. No limite, a grande reescritura dos dois textos é pautada pela dobra no tempo, que une a resistência aos dois golpes. Como Candido faz questão de explicitar no texto de 1967, fazendo alusão a um senso de repetição quase alegórico, “em 37, veio o golpe de Estado e o advento da fórmula ao mesmo tempo rígida e conciliatória, que encaminhou a transformação das estruturas econômicas pela industrialização. O Brasil de agora deitava os seus galhos, ajeitando a seiva que aquelas raízes tinham recolhido" (p.21).

\section{SOb A SOMBra de MÁrio: A CONSTRUÇÃo \\ DA MEMÓRIA “MODERNISTA”}

No "Plataforma da nova geração", Candido faz apenas a primeira referência a Sérgio Buarque. ${ }^{6}$ A aproximação entre os dois começava a acontecer justamente naqueles últimos e atribulados anos de Guerra e Estado Novo. Nesse período, os dois militaram em prol da profissionalização do campo intelectual no Brasil, com a Associação Brasileira dos Escritores (fundada em 1942), e, em 1945, ambos participaram ativamente do I Congresso Brasileiro de Escritores. Além de certas demandas urgentes, como a discussão sobre o recolhimento de direitos autorais e assistência ao escritor, o congresso teve o papel de demarcar publicamente uma posição política contrária à ditadura por meio de uma declaração de princípios (Lima, 2010, p.57).

Estamos diante de um dos capítulos fundamentais do processo de construção da memória "modernista". Daniel Faria e Marcelo Moreschi assinalaram a complexidade desse processo, procurando demonstrar como os próprios intelectuais ligados à identidade "modernista" constroem sua história em disputas pela formação de um cânone literário que se consolida na década de 1960, "sobretudo devido a Antonio Candido", e ganha uma “expressão editorial massiva" na década seguinte (Faria, 2006, p.7-8). O que se pode adicionar a essa reflexão é apontar para o papel das disputas travadas entre as décadas de 1930 e 1950 e, mais especificamente, projetar na década de 1940 um ponto 
de inflexão crucial. Nesse momento, Sérgio Buarque e Antonio Candido trabalham para dar sentido ao que será o embrião da "radicalidade", amalgamando os significados atribuídos à especialização da atividade crítica e à militância política.

Mário de Andrade teve papel importante nesse processo. Não é à toa que, em carta escrita a Rodrigo Melo Franco de Andrade, pouco antes de falecer em 1945, ele tenha classificado o evento como o "coroamento" de sua carreira (Andrade, 1981, p.186-187). Desde 1941, no artigo inaugural da revista Clima, ele havia declarado que a nova geração, formada nas novas faculdades de filosofia, continuava a "missão" modernista, a dissolver a tradição de uma crítica impressionista com o desenvolvimento de uma consciência técnica e especializada (Andrade, 1941, p.10-19). Esse sentido de missão da crítica especializada é reforçado, sobretudo por Candido, em seus textos na própria revista Clima (Pontes, 1998, p.59-61) e, posteriormente, nas suas colunas "Notas de Crítica Literária” (Folha da Manhã, 1943-1945) e no Diário de São Paulo (1945-1947).

Os significados atribuídos ao termo "radical" nas décadas de 1970 e 1980, que orientam o sentido de um engajamento intelectual de esquerda, dependem, portanto, desse passo fundamental da memória modernista na atribuição desses sentidos tão especiais ao termo "missão". Não surpreende o sentido original escatológico-cristão do termo, no sentido de que missão se aproxima da klesis da Epístola de Paulo aos romanos (cf. Agamben, 2000, p.25-30); trata-se de uma assinatura "andradiana" na sua cunhagem. O autor era conhecido pelo recurso a metáforas cristãs na construção da sua persona. Enquanto Daniel Faria observou, agudamente, os sentidos do sacrifício enquanto paixão, Ricardo Benzaquen de Araújo captou os sentidos da ideia de superação na aproximação aos seus interlocutores epistolares, em especial a Drummond (Faria, 2014, p.304-305; Araújo, 2014, p.182-183).

“Missão” era um termo que calava fundo nas relações entre Mário de Andrade e Sérgio Buarque. Desde que se mudou de São Paulo para o Rio de Janeiro, Sérgio foi imbuído pelo amigo mais velho de trabalhar na divulgação dos ideais do grupo de jovens paulistas. Em suas palavras, em carta de 8 de maio de 1922, "é preciso que não te esqueça que fazes parte dela. Trabalhas pela nossa Ideia, que é uma causa universal e bela, muito alta" (em Monteiro, 2012, p.19). Saltando para o momento de despedida, ainda em abril de 1945, logo depois da morte de Mário, Sérgio apresentou o necrológio do "mestre" morto na Associação Brasileira dos Escritores, aludindo ao Congresso como um coroamento e lembrando que, no limite, a missão da carreira do "líder 
morto" era o compromisso com a desmistificação da profissão de letras e da especialização desse campo (Holanda, 1996, v.1, p.371-372).

A questão chave é a forma com que Sérgio Buarque reelabora a ideia de "missão" do intelectual, no contexto do imediato pós-Segunda Guerra Mundial, considerando os seus desdobramentos locais, como a guinada na construção da memória modernista, com a morte de Mário de Andrade e com o fim do Estado Novo, bem como os desdobramentos mundiais, com a revisão dos valores que culminaram no nazismo e no fascismo. Esse tratamento da questão envolvia justamente a fusão entre a especialização das atividades intelectuais e a postura política e combativa com relação aos valores democráticos. A força que ganha ideia de engajamento do intelectual no pós-Segunda Guerra Mundial pode ser vista como um fenômeno global, indo muito além do contexto brasileiro. Já tive oportunidade de observar que, no final dos anos 1940, em crítica da obra Apologia da história, de Marc Bloch, o próprio Sérgio Buarque assinala que as ciências sociais, em particular a história, deveriam atender às demandas mais imediatas do presente (Nicodemo, 2008, p.37-42). Uma postura combativa deveria ser adotada pelos historiadores, especialmente no que diz respeito ao combate às pulsões nacionalistas e autoritárias, que haviam levado à ascensão dos totalitarismos e seus resultados trágicos.

Somos projetados, portanto, no interior do ambiente de revisão da primeira para a segunda edição de Raízes do Brasil. A obra é profundamente alterada em pelo menos dois aspectos: o primeiro é o "adensamento da erudição histórica” (Eugênio, 2011, p.400-408), com ampliação considerável na utilização de notas e recursos consistentes com a historiografia moderna do período (Nicodemo, 2014b, p.49-52); o segundo é a adoção de um viés progressista e democrático (Waizbort, 2011, p.57), relacionado com o apagamento e/ou diluição de elementos inconsistentes com essa posição. Quando se indaga sobre o que ocorreu entre 1936 e 1948 que levou o autor a mudar tanto, não se pode perder de vista a ligação intrínseca entre produção intelectual e compromisso político, pois coincide justamente com as atribuições de sentido à "missão" na sua crítica literária de finais da década de 1940.

Em “Missão e profissão”, publicado em agosto de 1948, Sérgio Buarque estabelece um diagnóstico dos males de nossa formação intelectual caracterizada por um gosto que se "detém nas aparências mais estreitamente ornamentais" e que produz em seus adeptos certo "prestígio estranho à vida intelectual e artística", tradição que define como "patriciado" intelectual (Holanda, 1996, v.2, p.39). Ao fazer isso, o autor atualiza um tema central em Raízes do Brasil 
que é o das permanências rurais e patrimonialistas na cultura do Estado independente (tema tratado no capítulo VI, "Novos tempos"). O tema principal gravita sobre a nossa inaptidão ao liberalismo e à ética do trabalho e como a cultura no país independente, cultivada nas leituras francesas, não deixava de ser uma atualização de formas arcaicas de manutenção do poder. A "missão" do intelectual comprometido com os ideais do modernismo era então romper com a tradição patriarcal diagnosticada em Raízes. Recorrendo a termos de Mário de Andrade, uma "verdadeira consciência técnica profissional" seria alcançada com "modéstia, inquirição metódica e perseverança" (Andrade, 1974 , p.189) que poderiam ganhar com a profissionalização do campo acelerada pelas gerações formadas nas faculdades de filosofia. Não por acaso, pequenas alterações foram inseridas na segunda edição da obra para reforçar esse sentido combativo (Nicodemo, 2014a, p.43-44).

\section{Os SENTIDOS DA FORMAÇÃO: COMBATE NA CRÍTICA LITERÁRIA E NA HISTÓRIA DA LITERATURA}

Em 1991 Antonio Candido publicou os originais inacabados sobre literatura colonial de Sérgio Buarque, sob o título de Capítulos de literatura colonial (Holanda, 1991). O aparecimento desse texto ajudou a iluminar aspectos fundamentais da colaboração entre os dois autores, na medida em que aponta para um debate com Formação da literatura brasileira (1959). De início, as obras foram escritas praticamente ao mesmo tempo; ambas foram encomendadas em meados da década de 1940 e destinadas a compor coleções sobre história da literatura nacional. Sérgio recebeu a encomenda de Álvaro Lins para uma coleção que organizava junto à editora José Olympio, mas acelerou a escrita apenas nos primeiros anos da década de 1950, especialmente no período em que esteve na Itália (1952-1954). Candido recebeu a encomenda do editor José de Barros Martins, da Martins Editora (originalmente endereçada a Mário de Andrade), passou cerca de 6 anos escrevendo uma primeira versão, lida por Sérgio Buarque em 1951; após uma interrupção, retomou o trabalho, realizando uma revisão entre 1955 e 1957 (Candido, 2000, p.10).

Ambos os críticos eram conscientes dos limites e problemas de se propor uma história da literatura naquele momento, e estavam atentos a vogas literárias que defendiam a autonomia do texto literário como new criticism, o imanentismo e a estilística (Nicodemo, 2014a, p.57-80). Tendo-se consolidado no 
século XIX segundo um prisma nacional e, consequentemente, sob a base de critérios políticos, a disciplina da "história da literatura" carregava consigo uma série de vícios discutíveis. Nesse contexto, ambos compartilharam leituras de obras recém-publicadas, tais como Mimesis, de Erich Auerbach (1948) e Literatura europeia e Idade Média Latina de Ernst Robert Curtius (1946), que podiam oferecer soluções alternativas aos problemas de método, temas e recortes tradicionais. ${ }^{7}$ No entanto, o problema dos dois estava posto no Brasil, pois a "missão" era de expurgar a tradição intelectual nacionalista, que remontava ao século XIX. Não era, portanto, questão de uma simples necessidade de atualização de um debate teórico, mas sim de buscar novas teorias que dessem uma resposta satisfatória a exigências políticas.

Os inimigos da tradição "radical" mereceriam um artigo autônomo, com casos como o de Gilberto Freyre (ou Menotti del Picchia e Oliveira Vianna, entre outros), que passa por uma bateria de críticas, tanto de Candido, no próprio texto da "Plataforma", quanto de Sérgio Buarque, na segunda edição de Raízes e na recepção a Sobrados e mucambos. Na crítica literária, Candido e Sérgio estavam alertas para reciclagens das tendências nacionalistas que apareciam revestidas de um sentido de novidade com a mobilização de conceitos do debate internacional, como também foi o caso de Afranio Coutinho, que publicava na década de 1950. Apesar de uma suposta intenção renovadora no recurso ao new criticism, seu trabalho é considerado "sem empenho de rigor, nem método crítico, uma obra mais de divulgação do que de análise" (Holanda, 1979, p.165). Candido, no prefácio à segunda edição do O método crítico de Sílvio Romero, afirma que Coutinho repetia os equívocos românticos do próprio Romero (Candido, 1988, p.13-14).

Em Capítulos e Formação a resistência a um nacionalismo acrítico aparece transposta em ímpeto para historicizar o período colonial brasileiro, enfatizando que a nacionalidade não deveria ser projetada teleologicamente na interpretação literária. Isso não significa que fossem livres, nem que desejassem se livrar de um paradigma nacional. É justamente por isso que ambos transformam esta pergunta em problema chave de suas obras: em que condições podemos falar na literatura como campo onde a cultura europeia toma cores próprias e cria condições de autonomia, ou seja, vai progressivamente se transformando no que identificamos como cultura nacional? E mais do que isso, em que medida podemos considerar este processo, o da produção da nacionalidade, em um plano de historicidade que se projeta ainda ao futuro, como uma missão inacabada? 
Em Formação os estilos compreendem as formas pelas quais a cultura se produz e se difunde fazendo da literatura um “sistema” (Candido, 2000, p.23). O barroco é excluído por não se enquadrar como um período marcado pela "continuidade ininterrupta de obras e autores, cientes quase sempre de integrarem um processo de formação literária" (p.24). O “arcadismo" é um "momento decisivo", pois dispõe embrionariamente os elementos do "sistema". Por isso, vai de 1750, "inicio da atividade literária de Cláudio", a 1836, lançamento da revista Niterói, ou seja, primeira iniciativa significativa, explícita e "consciente" de uma literatura própria (p.67). Assim, a obra propõe-se desde sua introdução a ser uma "história dos brasileiros no desejo de ter sua literatura”, ou seja, trata de maneira positiva-construtiva da história e da pré-história da consciência nacional. Candido indica, pouco a pouco, em sua análise dos árcades, como a estilização literária da realidade local passa a exprimir um sentimento dual, problemas "vivos" de uma sociedade cheia de paradoxos; em suas próprias palavras, "esforço de exprimir, no plano da arte, e dentro dos moldes cultos, a realidade e os problemas de sua terra” (p.88).

Talvez seja possível identificar aí o momento em que Candido toma para si a ideia motora de Raízes do Brasil, já que a sociedade e a cultura não nascem, moldam-se como resultado da adaptação de formas europeias às circunstâncias locais. Não se trata aqui simplesmente das ideias da primeira edição, mas sobretudo da incorporação de elementos que são reforçados com a segunda e com a terceira edição. Nas palavras de Sérgio Buarque, que só tomaram a forma que conhecemos em 1956, "o fato dominante e mais rico em consequências" em nossa formação se pauta pela "tentativa de implantação da cultura europeia", por meio da acomodação de "formas de convívio", "instituições" e "ideias" em um "ambiente muitas vezes desfavorável e hostil”, marcado por "condições adversas" (Holanda, 1995, p.31).

Essa convergência tão grande entre os dois intelectuais não impede que apareçam discordâncias importantes. Sérgio Buarque evita deliberadamente responder à questão da formação da consciência nacional, dando um tratamento estético e formal para o problema da transposição da realidade local em matéria literária. Atento à dinâmica dos topoi, lugares comuns literários, demonstra em seu livro a gênese de tópicas próprias, ou seja, analisa como se configura um acervo de formas literárias que se emancipam progressivamente de sua matriz europeia, tendo como interface o longo e persistente período barroco. Nesse ponto Capitulos aprofunda Raízes, pois trata, do ponto de vista da cultura e da literatura, das permanências de formas arcaicas avessas ao 
mundo moderno, dramatizadas na resistência do gênero épico, típico do que conhecemos como Antigo Regime, aos influxos de novas tendências como o arcadismo. Assim como na obra de 1936, esse movimento descompassado de adaptação gera formas que podemos considerar próprias, identificadas pelo autor como variantes do "mito americano" (Holanda, 1991, p.61-62).

Como tratamos de uma sociedade quase inteiramente iletrada, não há como discutir a irradiação de padrões e imagens literárias sem levar em consideração as modalidades musicais como a modinha, as operetas árcades, além de outras manifestações de origem afro-brasileira ou indígena, como o cururu ou os lundus. Esse é um tema presente em Formação, já que na difusão dessas canções está em jogo o embrião de uma cultura própria, cabocla ou caipira. Isso aparece não só nas linhas sobre Caldas Barbosa, mas nas sugestões que atribui de um "sabor quase popular" à poesia lírica de Silva Alvarenga (Candido, 2000, p.135-142).

O tema remetia aos estudos de Mário de Andrade sobre música e cultura popular brasileira. Em 1944, enquanto escrevia a obra sobre o padre Jesuíno Monte Carmelo, Mário trocou experiências de pesquisa com Sérgio Buarque que incluíram debate sobre o lundu, "a primeira forma negra que se 'nacionalizou’ brasileira, não só subindo pro salão burguês e se difundindo por todas as classes da sociedade brasileira, como por ser a primeira fusão dos elementos técnicos e formais afronegros e fusoeuropeus musicais. Fusão que daria na música folclórica atual" (Monteiro, 2012, p.139). ${ }^{8}$ Não por acaso, a tese de Candido, apresentada em 1954, Parceiros do Rio Bonito (livro publicado em 1964) se originou no esteio dessa discussão sobre a incorporação de elementos religiosos de origem lusitana gerando a cultura cabocla. Nas palavras do próprio Candido, "nasceu de uma pesquisa sobre poesia popular, como se manifesta no Cururu - dança cantada do caipira paulista", que incorpora elementos religiosos do colonizador e passa a integrar a cultura cabocla (Candido, 2001, p.11; Candido, 1956).

\section{O CAIPIRA, O BANDEIRANTE E O PROBLEMA DA DEMOCRACIA}

A revisão de Raízes e sua reapropriação colaborativa não se pautam apenas por descontinuidade e apagamentos, mas sobretudo por um desejo de aprimoramento desta mesma ideia tão insistente: como formas nacionais nascem no descompasso entre a ordem burguesa e moderna que se instaura e a 
persistência de formas tradicionais resultantes de um longo processo de adaptação do europeu no Novo Mundo. Sob essa ótica, o bloco de textos que compreende Monções (1945) e Caminhos e fronteiras (1957) e a obra Parceiros do Rio Bonito (1964) se fundem num grande projeto, que se complementa, dedicado a compreender a interiorização do Brasil e suas resultantes culturais. Essa colaboração está muito longe de ser um segredo. Candido reconhece, diversas vezes, que a cultura caipira estudada no volume nada mais é do que a continuação e aprofundamento da cultura bandeirante analisada por Sérgio (Candido, 2001, p.46-47, 276; Jackson, 2002, p.53-55). Sérgio, por sua vez, reconhece que a ideia de unir os textos sobre a expansão paulista, em sua maioria escritos na segunda metade da década de 1940, em um volume, Caminhos e fronteiras, fora do amigo (Holanda, 1994, p.15).

Pensando na questão do recorte temporal, Caminhos e fronteiras trata da expansão paulista por caminhos terrestres, das entradas e das bandeiras, concentradas nos séculos XVI e XVII. Monções trata do processo de expansão a partir do planalto paulista, sobretudo pelas vias fluviais, ocorrido principalmente no século XVIII. Parceiros do Rio Bonito, enquanto estudo sociológico, trata do problema no presente, mas recorre frequentemente ao passado, dando um lugar considerável para os relatos dos séculos XVIII e XIX.

Enquanto representações da mesma figura em planos temporais distintos, o bandeirante e o caipira remetem a uma população pobre que se adapta ao meio em busca da sobrevivência, seja aprendendo a se guiar e se comportar na mata nas "rudes vias de comunicação, abertas pelos naturais do país" (Holanda, 2000, p.16) ou nos rios, graças às técnicas de navegação e tecnologia de construção dos próprios barcos. Em todos os casos, o uso dos recursos nativos não se dá sem a "recuperação do legado europeu e amálgama de tradições que resulta em algo novo" (Wegner, 2000, p.161); ou nas palavras de Candido, "a combinação dos traços culturais indígenas e portugueses obedeceu ao ritmo nômade do bandeirante e do povoador, conservando as características de uma economia largamente permeada pelas práticas de presa e coleta" (Candido, 2001, p.48).

A alimentação é um campo de análise estratégico para ambos, já que necessariamente conectado com a sobrevivência e imposições do meio. Caminhos e fronteiras trata da acomodação de técnicas adventícias e locais na apicultura (Holanda, 1995, p.46-48), e no cultivo e beneficiamento do milho e da mandioca, ambos produtos americanos, mas então processados por técnicas europeias tais como os moinhos e o monjolo (p.181-190). Candido trabalha com o 
mesmo tema olhando, comparativamente, para o passado, na cultura tradicional bandeirante (Candido, 2001, p.61-74), e para o presente, no espectro estudado no município de Bofete, em 1948 e 1954, para captar as mudanças impostas pela cultura urbana e industrial.

Em ambos os casos ecoa a figura do aventureiro de Raízes do Brasil. Em Monções o autor mostra como, aos poucos, o aventureiro colonizador "domesticou-se"; em suas palavras, "é inevitável pensar que o rio, que as longas jornadas fluviais tiveram uma ação disciplinadora e de algum modo amortecedora sobre o ânimo tradicionalmente aventuroso daqueles homens" (Holanda, 1990, p.72). Era então preciso criar condições de segurança mínimas para a navegação fluvial, colonizando a terra, criando paragens fixas nas jornadas fluviais por meio da fixação dos "moradores mais ou menos numerosos", "em todas as barras principais e junto aos sítios em que se fazia mais perigosa a navegação" (p.37). Em Parceiros o "caráter" "provisório da aventura" (Candido, 2001, p.48) permanece como forma de se colocar no mundo do caipira. Como sugere Luiz Carlos Jackson, "o resultado é uma sociedade que se transforma muito pouco no decorrer do tempo, e que recorre à tradição como recurso de ajustamento à nova situação" (Jackson, 2002, p.55). Talvez se possa dizer que o livro aprofunda um senso dramático, deslocamento no vazio do arcaico no moderno, já que o universo caipira parece condenado a acabar. Banido do próprio tempo, o caipira é incapaz de se adaptar ao mundo urbano, "a solidariedade" decai e "se comercializa", "a indústria doméstica se atrofia", "mas o poder aquisitivo não comporta a substituição satisfatória pelos produtos manufaturados", os velhos "utensílios e instrumentos são desprezados - mas novos não se tornam acessíveis", "a caça e a pesca se reduzem", "mas não podem ser substituídas pela alimentação cárnea do comércio” (Candido, 2001, p.274). Assim, uma forma própria e tradicional é perdida, mas sem a conquista de uma nova.

Monções, Caminhos e Parceiros se colocam de fato em continuidade com Raizes, pois identificam o embrião de uma sociedade autóctone emanando das forças contraditórias do tecido social. Os termos não perdem a sua remissão romântica no vitalismo e no organicismo, já que "cabe ao povo descobrir e realizar a sua virtude própria” (Waizbort, 2011, p.43), a acomodação do moderno deveria emergir "das suas necessidades específicas e jamais das escolhas caprichosas” (Rodrigues, 2005, p.82). Nessa medida, os livros posteriores aprofundam a reflexão sobre o lento processo da "revolução brasileira": a transição do mundo rural para o mundo urbano, dissolvendo nossas raízes ibéricas. $\mathrm{Na}$ Europa, o mundo medieval e feudal se dissolvia frente ao mundo moderno 
industrial e trazia consigo possibilidades de desenvolvimento de formas de governo impessoais. Porém, na América portuguesa, ancorada no personalismo, essa transição se colocava em termos de um impasse. Uma impossibilidade de transição que abre caminho para a irrupção do autoritarismo, com as elites oligárquicas e o caudilhismo, impondo transformações de fora para dentro (Waizbort, 2011, p.48-49).

Mas o que muda do primeiro Raízes do Brasil para as edições posteriores em face dessa trajetória de apropriação e desapropriação colaborativa presente em Monções, Caminhos e fronteiras e Parceiros do Rio Bonito? No primeiro Raízes a democracia é um "lamentável mal-entendido", porque enquanto forma de governo ela é inorgânica e, portanto, inviável. Com a revisão de valores operada na década de 1940, a semântica do termo "democracia" é sutilmente alterada, perdendo acepção rígida, enquanto forma de governo no bojo da filosofia política, e se aproximando dos significados de uma confluência de valores e demandas que vão sendo gestados na medida em que a sociedade se forma. Assim, o fundamento da democracia, que é, no limite, a soberania, é deslocado, passando a se assentar na precariedade, inconclusão do conflitivo tecido social (Rodrigues, 2005, p.57-58). A modernidade e o projeto civilizacional burguês, encampados pelo Estado, também são ressignificados; enquanto o primeiro Raízes é marcado por certo otimismo de uma inserção necessária e quase inevitável do Brasil na ordem moderna, as obras posteriores de Sérgio Buarque vão se distanciando dessa visão, considerando a modernidade como um processo problemático e cheio de contradições. Trata-se de uma restituição da condição de potência aos atos e fatos históricos, de maneira que a formação nacional passa a ser mediada pela inconclusão, representada por um ainda não, cuidadosamente incluído na revisão dos parágrafos da segunda edição de Raízes (Nicodemo, 2014b, p.46-49).

Radical, portanto, é olhar para o processo de formação nacional como um horizonte ainda incompleto, que deve ser alterado mediante a restituição de voz e de complexidade aos sujeitos históricos, em constante balanço entre passado e futuro. Candido dá uma solução exemplar ao problema em Parceiros, quando a conservação de traços tradicionais ganha um sentido de "defesa grupal e cultural" (Candido, 2001, p.274). Assim como em outras correntes da época, tais como o marxismo britânico, a afirmação de futuros alternativos ao capitalismo orienta o estudo sobre os significados que as formas tradicionais ganham na resistência à modernidade (Dworkin, 1997, p.38). 


\section{A DEMOCRACIA É DIFÍCIL: MEMÓRIA, ÉTICA E HERMENÊUTICA}

Este texto procurou "escavar" as camadas de memória subjacentes ao prefácio a Raízes do Brasil de Antonio Candido, atentando para o complexo trabalho de memória envolvido em cada momento. Vimos que de um modo geral as interpretações do Brasil de Sérgio Buarque de Holanda e Antonio Candido se amalgamam, na medida em que produzem e atualizam sentidos sobre o engajamento intelectual no século XX. A noção de "radicalidade" pode ser entendida, assim, como um dispositivo produzido no entrecruzamento entre a memória da ditadura e a esperança de democratização do Brasil, contando tanto o Estado Novo, quanto a ditadura civil-militar. Nesse sentido espero que o enquadramento proposto neste artigo possa contribuir não só para os interessados em Candido e Sérgio Buarque, mas para o debate sobre os novos enquadramentos da história da historiografia e da história intelectual.

O problema da memória é complexo e envolve uma sobreposição de planos temporais e curto-circuitos de significados. Trata-se de um esforço hermenêutico de historicizar os condicionantes das nossas próprias categorias de análise e, no limite, da nossa própria visão de Brasil. Em alguma medida, este artigo pode ser considerado um esforço de biografia intelectual cruzada, pois incorpora os pressupostos autorreflexivos da histoire croisée (Werner; Zimmermann, 2006, p.31-33), ao mesmo tempo que se aproveita de um adensamento na reflexão sobre a memória. Um bom exemplo a respeito disso é Gregor Feindt (2014), que propõe a análise da memória por meio de uma inversão na relação entre presente e passado, "a reconstrução do significante mnemônico clama por traçar as interpretações mnemônicas subsequentes no tempo", assim podemos explicar melhor por que algumas interpretaçoes tornaram-se predominantes em detrimento de outras, bem como "interpretações posteriores reapropriam anteriores novamente" (Feindt, 2014, p.36, trad. nossa).

Este texto não procurou sistematicamente apurar se Antonio Candido e Sérgio Buarque são responsáveis pela construção de um cânone interpretativo ou de uma memória acadêmica, mas ao mesmo tempo não se pode deixar de reconhecer que a leitura do artigo pode levar a essa conclusão. Em termos propostos por Paul Ricoeur, pode-se questionar se o trabalho de memória operado pelos intelectuais brasileiros constitui em alguma medida um "abuso" ou "manipulação" da memória (Ricoeur, 2000, p.102-104).

A provável resposta para essa investigação é negativa. Em primeiro lugar, porque não há qualquer veto em mudar de ideia e revisar suas obras; em 
segundo, porque todo trabalho de escrita, inclusive este que ora se faz, pressupõe, em alguma medida, a manipulação da memória e a escrita de si. Mas, sobretudo, porque um cânone "radical" não representa outra coisa senão uma forma de resistência legítima ao autoritarismo. Mesmo a noção de que a interpretação "radical" do Brasil, da qual os dois protagonistas são cúmplices, seja "vitoriosa" por ter se tornado um cânone, deve ser problematizada. O projeto intelectual encampado por Candido e Sérgio sofreu sérias derrotas no plano político e institucional, que devem ser consideradas, nessa avaliação, da dissolução do Departamento de Cultura da prefeitura de São Paulo, nos anos 1930, à reforma universitária e às aposentadorias compulsórias na USP, em 1969. O recurso à memória, nesse sentido, é uma forma natural de resistência. Outra questão importante é que esse movimento de ideias tem caráter global, e é relacionado com certos imperativos éticos delineados no pós-Segunda Guerra Mundial. Por isso, o trabalho de memória que une militância e análise em ciências sociais não está num patamar diferente das reações aos totalitarismos na Europa, nos Estados Unidos e na América Latina (ver Dworkin, 1997; Denning, 1998; Waltzer, 2002; Wald, 2002; Liucci, 2011).

Pensar uma escrita "democrática" da história depende justamente de um olhar autocrítico para agenda de trabalho que historiadores e cientistas sociais apresentam na articulação entre passado e futuro. Historicizar os condicionantes do nosso próprio olhar desconfiando das interpretações canônicas se apresenta, portanto, como um caminho necessário, mas que não se basta em si. Justamente aí reside o maior potencial crítico do pensamento de Antonio Candido e Sérgio Buarque de Holanda: na capacidade de adaptação e atualização do pensamento aos problemas de seu tempo.

\section{REFERÊNCIAS}

AGAMBEN, Giorgio. Il tempo che resta: un commento alla Lettera ai Romani. Torino: Bollati Boringhieri, 2000.

ANDRADE, Mário de. Aspectos da literatura brasileira. São Paulo: Livr. Martins, 1974. . Cartas de Trabalho: correspondência com Rodrigo Melo Franco de Andrade (1936-1945). Brasília: Ministério da Educação e Cultura, Secretaria do Patrimônio Artístico e Histórico Nacional, Fundação Pró-Memória, 1981. . Elegia de Abril. Clima, n.1, p.10-19, 1941.

ARAÚJO, Ricardo B. de. Um grão de sal: autenticidade, felicidade e relações de amizade na correspondência de Mário de Andrade com Carlos Drummond. História da Historiografia, n.16, 2014. 
BRESCIANI, Maria S. M. O charme da ciência e a sedução da objetividade: Oliveira Vianna entre intérpretes do Brasil. São Paulo: Ed. Unesp, 2005.

CANDIDO, Antonio. Formação da literatura brasileira. Belo Horizonte: Itatiaia, 2000. . Introdução. In: HOLANDA, Sérgio B. de. Capítulos de literatura colonial.

Org., introd. e notas de Antonio Candido. São Paulo: Brasiliense, 1991.

. O método crítico de Silvio Romero. São Paulo: Edusp, 1988.

. Os parceiros do Rio Bonito. São Paulo: Ed. 34, 2001.

. Possíveis raízes indígenas de uma dança popular. Revista de Antropologia, v.IV, n.1, 1956.

. Prefácio. In: HOLANDA, Sérgio B. de. Raízes do Brasil. Brasília: Ed. UnB, 1963.

. Radicalismos. Estudos Avançados, v.4, n.8, 1990.

. Sérgio em Berlin e depois. Novos Estudos, n.3, 1982.

. O significado de Raizes do Brasil. In: HOLANDA, Sérgio B. de. Raizes do Brasil. 26.ed. São Paulo: Companhia das Letras, 1995.

. Textos de intervenção. Sel., apresent. e notas de Vinicius Dantas. São Paulo:

Duas Cidades; Ed. 34, 2002.

CARVALHO, Raphael. A escrita de si de Sérgio Buarque de Holanda nos anos 1970 (notas para estudo). Tempos históricos, v.19, 2015.

DENNING, Michael. The cultural front: The laboring of American culture in the twentieth century. London: Verso, 1998.

DIAS, Maria Odila L. da S. Sérgio Buarque de Holanda, historiador. In: SÉRGIO Buarque de Holanda. São Paulo: Ática, 1985.

DOSSE, François. Gilles Deleuze \& Félix Guattari: Intersecting lives. New York: Columbia University Press, 2010.

DWORKIN, Dennis. Cultural Marxism in Postwar Britain: History, the New Left, and the origins of cultural studies. Durham, NC: Duke University Press, 1997.

EUGÊNIO, João K. Ritmo espontâneo: organicismo em Raízes do Brasil de Sérgio Buarque de Holanda. Teresina: Ed. UFPI, 2011.

FARIA, Daniel. Historicidade modernista: a brasilidade entre passado e futuro. In: SILVA, Ana R.; NICOLAZZI, Fernando; PEREIRA, Mateus H. Contribuições à História da Historiografia Luso-brasileira. São Paulo: Hucitec, 2014.

. O mito modernista. Uberlândia: Ed. UFU, 2006.

FEINDT, Gregor (et al.) Entangled memory: toward a third wave in memory studies. History and Theory, n.53, 2014.

FRANZINI, Fábio. À sombra das palmeiras: a Coleção Documentos Brasileiros e as transformações da historiografia nacional (1936-1959). Rio de Janeiro: Ed. Casa de Rui Barbosa, 2010.

.; GONTIJO, Rebeca. Memória e história da historiografia no Brasil: a invenção de uma moderna tradição, anos 1940-1960. In: SOIHET, Rachel et al. Mitos, 
projetos e práticas políticas: memória e historiografia. Rio de Janeiro: Civilização Brasileira, 2009.

GASPARI, Elio. Uma cabeça que bate contra a maré: Wanderley Guilherme dos Santos, elitista e marginal, vencedor de causas perdidas. Veja, 18 maio 1994, p.40-43.

HOLANDA, Sérgio B. de. Caminhos e fronteiras. 3.ed. São Paulo: Companhia das Letras, 1995.

. Capitulos de literatura colonial. Org., introd. e notas de Antonio Candido. São Paulo: Brasiliense, 1991.

. Corpo e Alma do Brasil: entrevista a Bolivar Lamounier, Ernani da Silva Bruno, Laura de Mello e Souza e Maria Tereza S. Petrone. Novos Estudos, n.69, 2004.

. O espírito e a letra: estudos de crítica literária. Org., introd. e notas de Antonio Arnoni Prado. 2v. São Paulo: Companhia das Letras, 1996. . Monções. 3.ed. São Paulo: Brasiliense, 1990. . Raízes do Brasil. 1.ed. Rio de Janeiro: Livr. J. Olympio, 1936. . Raízes do Brasil. 26.ed. São Paulo: Companhia das Letras, 1995. Tentativas de mitologia. São Paulo: Perspectiva, 1979.

JACKSON, Luiz. A tradição esquecida: os Parceiros do Rio Bonito e a sociologia de Antonio Candido. Belo Horizonte: Ed. UFMG, 2002.

LIMA, Felipe V. O Primeiro Congresso Brasileiro de Escritores: movimento intelectual contra o Estado Novo (1945). Dissertação (Mestrado) - FFLCH, Universidade de São Paulo. São Paulo, 2010.

LIUCCI, Raffaele. Spettatori di un naufragio: gli intellettuali italiani nella Seconda Guerra Mondiale. Torino: Einaudi, 2011.

RIDENTI, Marcelo. Em busca do povo brasileiro: artistas da revolução, do CPC à era da TV. Rio de Janeiro: Record, 2000.

ROCHA, João Cezar de C. O exílio como eixo: bem-sucedidos e desterrados. In: MONTEIRO, Pedro M.; EUGÊNIO, João K. (Org.) Sérgio Buarque de Holanda: perspectivas. Campinas: Ed. Unicamp; Rio de Janeiro: Ed. Uerj, 2008.

SANCHES, D. As escritas de (e sobre) Raizes do Brasil: possibilidades e desafios à história da historiografia. História da Historiografia, Ouro Preto: Ufop, n.9, 2012. MONTEIRO, Pedro M. A queda do aventureiro: aventura, cordialidade e os novos tempos em Raízes do Brasil. Campinas: Ed. Unicamp, 1999.

. Signo e desterro: Sérgio Buarque de Holanda e a imaginação do Brasil. São Paulo: Hucitec, 2015.

. (Org.) Mário de Andrade e Sérgio Buarque de Holanda: correspondência. São Paulo: Companhia da Letras; Instituto de Estudos Brasileiros (IEB-USP); Edusp, 2012. p.138-168.

MORAES, José V.; REGO, José M. Conversas com historiadores brasileiros. São Paulo: Ed. 34, 2002. 
MORESCHI, Marcelo S. A façanha auto-historiográfica do modernismo brasileiro. Brazilian modernism as an auto-historiographical avant-garde. Santa Barbara, Calif.: University of California, 2010.

NAPOLITANO, Marcos. 1964: história do regime militar brasileiro. São Paulo: Contexto, 2014.

NICODEMO, Thiago L. Alegoria moderna: crítica literária e história da literatura na obra de Sérgio Buarque de Holanda. São Paulo FAP-Unifesp, 2014a.

. Os planos de historicidade na interpretação do Brasil de Sérgio Buarque de Holanda. Historia da Historiografia, v.14, 2014b.

. Urdidura do vivido: Visão do Paraíso e a obra de Sérgio Buarque de Holanda na década de 1950. São Paulo: Edusp, 2008.

PONTES, Heloisa. Destinos mistos: os críticos do Grupo Clima em São Paulo (19401968). São Paulo: Companhia das Letras, 1998.

PRADO, Antonio A. (et al.) $3^{\circ}$ Colóquio Uerj: Sérgio Buarque de Holanda. Rio de Janeiro: Imago, 1992.

RICOEUR, Paul. La mémoire, l'histoire, l'oubli. Paris: Seuil, 2000.

RODRIGUES, Henrique E. Fronteiras da democracia em Sérgio Buarque de Holanda. Tese (Doutorado em Filosofia) - FFLCH, Universidade de São Paulo. São Paulo, 2005.

SILVA, Rafael. A morte do homem cordial: trajetória e memória na invenção de um personagem (Sérgio Buarque de Holanda, 1902-1982). Tese (Doutorado em História) - IFCH, Unicamp. Campinas, 2015.

WALD, Alan. Exiles from a future time: the forging of the mid-twentieth-century literary left. Chapel Hill, NC: University of North Carolina Press, 2002.

WAIZBORT, Leopoldo. O mal-entendido da democracia: Sérgio Buarque de Hollanda, Raízes do Brasil, 1936. Revista Brasileira de Ciências Sociais, v.26, n.76, 2011. . A passagem do três ao um. São Paulo: CosacNaify, 2007.

WALTZER, Michael. The company of critics: Social criticism and political commitment in the twentieth century. New York: Basic Books, 2002.

WEGNER, Robert. A conquista do oeste: a fronteira na obra de Sérgio Buarque de Holanda. Belo Horizonte: Ed. UFMG, 2000.

WERNER, Michael; ZIMMERMANN, Bénédicte. Beyond comparison: histoire croisée and the Challenge of Reflexivity. History and Theory, n.45, 2006.

\section{NOTAS}

${ }^{1}$ Mestre e Doutor em História Social pela Universidade de São Paulo (USP) e pós-doutor pelo Instituto de Estudos Brasileiros da USP (IEB-USP). Atuou como pesquisador na Università di Bologna (Itália, 2007), na University of Texas (EUA, 2009-2010), na Oliveira 
Lima Library/The Catholic University of America (2014) e na Stony Brook University (EUA, 2015). Autor de dois livros centrados na obra de Sérgio Buarque de Holanda: Urdidura do vivido (Edusp, 2008) e Alegoria moderna (Ed. Unifesp, 2014), dedica-se ao estudo do pensamento social brasileiro do século XX e seus desdobramentos teóricos. Atualmente é pesquisador do IEB-USP, Professor Adjunto do Departamento de História da Universidade do Estado do Rio de Janeiro (Uerj) e professor do Programa de Pós-Graduação em História da mesma instituição.

${ }^{2}$ O primeiro prefácio de Candido a Raizes do Brasil foi publicado na quarta edição, de 1963 . O texto sustenta de forma breve a ideia de que o livro "se tornou um clássico" e que "seus pontos de vista se tenham incorporado ao pensamento de uma geração" (CANDIDO, 1963, p.IX). No entanto, não menciona explicitamente a ligação do livro com a questão da democracia.

${ }^{3}$ Conforme sugeriu Wanderley Guilherme dos Santos em entrevista a Elio Gaspari, de 1994 (GASPARI, 1994), trabalhado de forma crítica por João Kennedy Eugênio em Ritmo espontâneo (EUGÊNIO, 2011, p.395-398) e por Pedro Meira Monteiro, em Signo e desterro (MONTEIRO, 2015, p.29-38, 205).

${ }^{4}$ Sobre o papel do próprio Sérgio Buarque na construção de sua imagem, ver: CARVALHO, 2015.

${ }^{5}$ Originalmente publicado em O Estado de S. Paulo de 15 jul. 1943, como parte de um inquérito realizado por Mário Neme. Utilizo uma reprodução incluída no volume Textos de intervenção, organizado por Vinicius Dantas (2002) que tem por base a compilação Plataforma de uma nova geração, organizada por Mário Neme e publicada pela editora Globo em 1945.

${ }^{6}$ Pouco depois, em agosto de 1944, Candido faz uma curta resenha de Cobra de vidro, no $13^{\circ}$ número da revista Clima. Já Sérgio Buarque se refere a Candido elogiosamente em abril de 1950, quando comenta a fortuna crítica de Marcel Proust no Brasil (HOLANDA, 1996, v.2, p.195-200).

${ }^{7}$ Waizbort demonstra o impacto da leitura de Mimesis em Antonio Candido e aventa a possibilidade de que Sérgio Buarque tenha lhe apresentado o livro (WAIZBORT, 2007, p.92-93). De fato, ambas as obras foram apreciadas por Sérgio Buarque no texto "Mimesis" em novembro de 1950.

${ }^{8}$ Ver as cartas de Mário de Andrade a Sérgio Buarque de Holanda de 23 e 29 de julho e de 7, 13 e 26 de dezembro de 1944, com apenas uma resposta de Sérgio conhecida, sem dia, mas de dezembro de 1944. Ao falar da questão Mário de Andrade também remete às ideias desenvolvidas no artigo "Lundu do Escravo", publicado em 1928 na Revista de Antropofagia (MONTEIRO, 2012, p.138-168). Em Capitulos, Sérgio Buarque discorda de Andrade e de Candido, procurando afastar o pretenso romantismo dessas fórmulas e propondo uma solução formal, na medida em que as tópicas árcades, tais como o melodrama metastasiano, fundiam-se com a lírica tradicional lusitana, resultando em imagens locais (HOLANDA, 1991, p.195).

Artigo recebido em 29 de junho de 2016. Aprovado em 26 de agosto de 2016. 